\title{
Emprego e Trabalho na América Latina:
} análise crítica sobre as informações da CEPAL (1995 - 2008) / Employment and work in Latin America: critical analysis on the informations of ECLAC (1995 - 2008)

José Pedro Cabrera Cabral* VANDA Micheli Burginski ${ }^{* *}$

Resumo: $O$ presente artigo tem por objetivo analisar as informações publicadas pela Cepal (1995-2008) acerca do emprego na América Latina. Segundo dados oficiais apresentados pela Cepal, entre 2002 e 2007 registrou-se na América Latina uma diminuição do desemprego de $11 \%$ para $8 \%$ afirmando uma tendência de crescimento econômico com a criação de novos postos de trabalho e, conseqüentemente, uma diminuição nos índices de pobreza. O que parece problemático nessas conclusões é que os índices de pobreza não acompanham os índices de diminuição de desemprego. Outro ponto importante da análise acerca desses indicadores está na forma como a Cepal interpreta a precarização do trabalho, separando trabalhadores que se encontram em setores vulneráveis dos trabalhadores de setores de baixa produtividade, fazendo diminuir os índices de desemprego. Os resultados do estudo apontam para a necessidade de uma releitura crítica dos dados apresentados por Organismos Internacionais.

Palavras-chave: Trabalho precarizado, Emprego, Desemprego, Pobreza, América Latina.

Abstract: This article aims to analyze the information published by ECLAC (1995-2008) on employment in Latin America.

\footnotetext{
* Professor do Curso de História da Universidade Federal do Tocantins - UFT, Doutor em História pela UNISINOS, Pós-doutorado em História pela UFRGS. E-mail: josepedro@uft. edu.br

** Professora do Curso de Serviço Social da Universidade Federal do Tocantins - UFT, Graduada em Serviço Social e mestre em Educação pela UFMT - Universidade Federal de Mato Grosso. E-mail: burginski@uft.edu.br
} 
According to official data presented by ECLAC, between 2002 and 2007, it was registered that the unemployment in Latin America was reduced from $11 \%$ to $8 \%$, affirming a trend of economic growth by creating new jobs and thus decreasing rates of poverty. What seems problematic in these findings is that poverty rates do not follow the rate of unemployment decrease. Another important point about the analysis of these indicators is the way the ECLAC interprets the precariousness of work, separating workers who are in vulnerable sectors of workers in low productivity sectors, causing lower rates of unemployment. The study results point to the need for a critical re-reading of the data submitted by International Organizations.

Key words: Precarious work, Employment, Unemployment, Poverty, Latin America.

\section{Introdução}

A principal fonte de renda na América Latina é resultado do trabalho. Segundo a Cepal - Comissão Econômica para América Latina e o Caribe -, esta corresponde a $79 \%$ da renda dos lares no continente. Assim, a promoção e criação de postos de trabalho e geração de renda se constituem na principal arma de combate à diminuição da pobreza e principal mecanismo de crescimento econômico dos países. O problema está em que o mercado de trabalho continua sendo um fator determinante das desigualdades sociais. Nos países latino-americanos a renda obtida através do trabalho representa entre $71 \%$ e $92 \%$ das desigualdades aferidas pelo índice de Gini ${ }^{1}$.

Na concepção cepalina, o mercado de trabalho representa uma peça fundamental tanto para o crescimento econômico como para a redução da pobreza. Assim, a criação de empregos, a melhoria das remunerações reais e a cobertura da proteção social dos trabalhadores ocupados seriam os mecanismos que

1 Para mais informações, veja-se o Panorama Social en America Latina 2008, publicado pela CEPAL. 
permitiriam traduzir o crescimento em melhorias da qualidade de vida dos trabalhadores, isto é, representado pela melhoria na renda das famílias latino-americanas. Apesar disso, a própria Cepal reconhece que a falta de acesso ao trabalho se constitui no principal responsável pelo aumento da pobreza e das desigualdades.

Conforme os dados apresentados por Sader (2003), a América Latina passou a viver a pior crise de desemprego, iniciada em 1995, ano da crise mexicana, chegando a cerca de 10\%, abrangendo um total de 18 milhões de pessoas. Na Argentina, o desemprego passou de 7,5\%, em 1990, para 21,5\% no começo de 2002. Quarenta e cinco por cento da população - 45 milhões de pessoas - não tinham emprego de qualidade em 1990, porcentagem que subiu para 50,5\%, isto é, para 53 milhões de habitantes. De cada dez empregos criados nesse período, sete estão no setor informal, no qual apenas dois de cada dez empregados têm acesso a benefícios sociais (SADER, 2003, p. 121).

A Cepal aponta que, a partir de 2003, se observa na América Latina uma tendência positiva do crescimento econômico que foi acompanhada pela diminuição do desemprego e pelo aumento de novos postos de trabalho e de geração de renda. Como conseqüência, segundo dados oficiais dos países da região, se registrou uma diminuição do desemprego de $11 \%$ para $8 \%$ entre 2002 e 2007 (COMISSÃO ECONÔMICA PARA A AMÉRICA LATINA E CARIBE, 2008a, p.105). Não casualmente este período corresponde ao acesso ao poder no continente de vários governos "progressistas", os quais têm implementado políticas de combate à pobreza e de diminuição das desigualdades sociais.

O que resulta curioso na análise da Cepal não são as coincidências nas propostas com estes mesmos governos progressistas e, sim, um alinhamento no que se refere a explicar e demonstrar significativas melhorias no mercado de trabalho, no crescente acesso ao mesmo e na diminuição do desemprego. 
Tanto os técnicos da Cepal como os tecnocratas dos respectivos Estados latino-americanos se esforçam em convencer-nos de que o fantasma do desemprego, o combate à pobreza e a diminuição das desigualdades sociais estão sendo eficientes e os resultados claramente apresentados pela Cepal.

Como ponto de partida para uma análise, tomemos os dados da Cepal sobre a evolução do desemprego no período de 1995 a 2008. No Anuário Estatístico da Cepal para América Latina foram publicadas as seguintes taxas de desemprego aberto: 10,0\% em 1995, 10,4\% em 2000, 9,1\% em 2005, 8,6\% em 2006, 7,0\% em 2007 e 7,5\% em 2008 (COMISSÃO ECONÔMICA PARA A AMÉRICA LATINA E CARIBE, 2008b, p. 54). Levando-se em consideração essas informações, levantamos a seguinte indagação: como é possível que os índices de desemprego diminuam nesta ordem e, concomitantemente, os indicadores de pobreza apontados não diminuam, necessariamente, na mesma ordem?

A explicação "técnica" para esta situação se encontra - segundo os técnicos da Cepal - no gradativo e constante aumento dos postos de trabalho registrados no continente desde 2003. Porém, esses dados omitem o que é fundamental: qual a "característica" desses novos postos de trabalho criados? A ocupação dos trabalhadores nesses postos de trabalho lhes garante uma remuneração que lhes permite sair da condição de pobreza? São indagações que procuraremos responder a seguir, tecendo uma análise crítica sobre os indicadores estudados pela Cepal.

\section{As interpretações da precarização do trabalho na con- cepção da Cepal}

Tendo como parâmetro o conceito de informalidade gerado pela Organização Internacional do Trabalho em 1972, a partir de um informe sobre os trabalhadores pobres do Kenya, Employment, 
incomes and equity: a strategy for increasing productive employment in Kenya, criaram-se várias categorias para explicar a precarização do trabalho. O setor informal ou o trabalho informal passou a ser uma categoria universal na qual, independentemente das interpretações, a maioria dos intelectuais e técnicos concorda que este tipo de trabalho era conseqüência da não absorção no mercado de trabalho formal de amplos contingentes populacionais, sendo este trabalho caracterizado pelo baixo nível salarial, a instabilidade, a falta de direitos trabalhistas e de proteção social.

Em uma versão atualizada do conceito de trabalho informal, com base na $15^{\text {a }}$ Conferência da Organização Internacional de Estatísticas do Trabalho ocorrida em 1993, e ratificada durante toda a década até chegar a 2008², a Cepal introduz uma discussão que gira em torno da produtividade - um conceito reelaborado pelo neoliberalismo na década de 1990 - que analisa a informalidade pela heterogeneidade da estrutura produtiva. Esta estrutura constaria de duas categorias ou setores: uma "formal" de produtividade média e alta, caracterizada por um maior nível de investimento, potencial de crescimento alto e proteção social efetiva, e outra "informal" de baixa produtividade, com um fraco potencial de crescimento e baixo ou nulo nível de proteção social.

$\mathrm{Na}$ categoria de "setores de baixa produtividade" se enquadram os trabalhadores independentes sem qualificação, os trabalhadores não remunerados - familiares ou aprendizes -, os pequenos proprietários, os assalariados de microempresas e o trabalho doméstico. Excluem-se desta categoria os trabalhadores

\footnotetext{
2 O conceito de emprego no setor informal se refere ao emprego gerado em empresas familiares (não constituídas formalmente em sociedades), que não cumprem com as regulamentações nacionais obrigatórias para a operação de unidades empresariais, e/ou não têm registros contábeis, seja por motivos econômicos, desconhecimento ou outros motivos. Esta definição compreende trabalhadores por conta própria, empresas que contam com empregados assalariados de forma contínua e podem contar também com trabalhadores auxiliares familiares.

3 Considera-se ocupação formal o total de trabalhadores com carteira assinada, inclusive os domésticos, militares e funcionarios públicos estatutários, os empregadores e trabalhadores por conta própria que contribuem para a Previdência Social.
} 
terceirizados e os trabalhadores vinculados ao associativismo e ao empreendedorismo - também uma contribuição do neoliberalismo - que em países como no caso de Argentina e Uruguai contam com uma longa tradição de trabalho cooperativo, ou, nos extremos, como no caso brasileiro, no qual a economia solidária se transformou na metade da década de 2000 em uma política pública de geração de trabalho e renda.

Para se ter uma visão ampla do significado da categoria de trabalho de baixa produtividade observe-se a Tabela 1:

\section{Tabela 1. América Latina (18 países) Características da inserção no trabalho. Totais nacionais - Valores percentuais 1990 - 2006 por faixa etária e sexo}

\begin{tabular}{c|c|c|c|c|c|c|}
\hline \multicolumn{4}{c|}{ Trabalhadores Vulneráveis* } & \multicolumn{3}{c|}{$\begin{array}{c}\text { Ocupados em Baixa } \\
\text { Produtividade** }\end{array}$} \\
\hline Faixa Etária & 1990 & 2002 & 2006 & 1990 & 2002 & 2006 \\
\hline 15 a 29 anos & 25,7 & 27,2 & 25,4 & 49,2 & 50,3 & 46,6 \\
\hline 30 a 64 anos & 36,5 & 37,3 & 35,7 & 54,0 & 51,9 & 49,8 \\
\hline $\begin{array}{c}\text { Homens 15 anos } \\
\text { a mais }\end{array}$ & 32,5 & 33,7 & 32,1 & 51,3 & 50,4 & 47,3 \\
$\begin{array}{c}\text { Mulheres 15 anos } \\
\text { a mais }\end{array}$ & 34,1 & 37,0 & 35,9 & 57,7 & 57,4 & 55,5 \\
\hline Total & 33,0 & 35,0 & 33,7 & 53,5 & 53,2 & 50,7 \\
\hline
\end{tabular}

Fonte: Elaborada com informações da CEPAL. Panorama Social de América Latina 2008. p. 132.

Observações:

* Inclui trabalhadores por conta própria e trabalhadores não remunerados.

**Trabalhadores empregados em setores de baixa produtividade no geral. Exclui dados da Colômbia.

A Tabela 1, elaborada com base nas informações da Cepal, abre uma velha polêmica que se apresenta como nova, ou seja, a divisão de uma categoria em duas: de um lado, trabalhadores vulneráveis e, de outro, trabalhadores em setores de baixa 
produtividade. Concretamente, quais são as diferenças entre ambas as categorias? Será que um trabalhador vinculado a setores de baixa produtividade não é também um trabalhador vulnerável? Observe-se como a Cepal conceitua estas categorias.

A Cepal vincula o trabalho informal com o trabalho em setores de baixa produtividade como conseqüência da heterogeneidade da estrutura produtiva que gera e mantém o setor informal, de forma bastante particular e endógena. Esta concepção do trabalho informal se desvincula do trabalho precarizado e, nos dados da Cepal, particularmente, do trabalho vulnerável, como se fossem categorias distintas. Qualquer trabalhador assalariado que não tenha acesso à proteção social, à legislação trabalhista, à estabilidade do trabalho e à remuneração digna se encontra em situação de vulnerabilidade. Porém, os técnicos da Cepal separam duas categorias que são essencialmente inseparáveis.

A concepção de informalidade também se aplica aos trabalhadores que se enquadram nos setores de baixa produtividade vinculados ao chamado "auto-emprego". Associativismo, cooperativismo, empreendedorismo e práticas de economia solidária formam parte dos setores de baixa produtividade. Neste caso, o Banco Mundial considera que a existência da economia informal se deve aos altos custos do trabalho e a uma burocracia muito complexa, que seriam os responsáveis por evitar o desenvolvimento de uma atividade econômica no marco formal.

Isto significaria que o auto-emprego seria uma decisão do trabalhador, que em determinado momento "optou" por formas de auto-emprego, desprezando a formalidade do vínculo trabalhista. Esta concepção se embasa no empreendedorismo promovido pelo neoliberalismo desde finais da década de 1980 e início dos anos de 1990. Esta pretensão terceiriza a responsabilidade dos empreendimentos de auto-emprego para o plano individual do trabalhador e tira o foco, ou a responsabilidade, tanto do Estado como do mercado de trabalho formal. 


\section{O conceito de trabalho decente}

O conceito de trabalho decente tem sua origem na Organização Internacional do Trabalho - OIT - em 1999. Retomado pela Cepal, pelo Pnud (Programa das Nações Unidas para o Desenvolvimento) e pela OIT em 2008 e sistematizado em um livro intitulado "Emprego, Desenvolvimento Humano e Trabalho Decente: a experiência brasileira recente", concebeuse a necessidade de uma oferta de trabalho produtivo e seguro, que respeite os direitos trabalhistas - principalmente a liberdade sindical, a negociação coletiva e a eliminação do trabalho infantil e do trabalho forçado - assim como a proteção social e as desigualdades de gênero (COMISSÃO ECONÔMICA PARA A AMÉRICA LATINA E CARIBE; PROGRAMA DAS NAÇÕES UNIDAS PARA O DESENVOLVIMENTO; ORGANIZAÇÃO INTERNACIONAL DO TRABALHO, 2008, p. 81).

Isto pressupõe que gerar trabalho decente necessitaria de uma ampla articulação de políticas macro e micro-econômicas com políticas sociais, de emprego e de mercado de trabalho que contribuíssem para o desenvolvimento estabelecendo uma junção entre direitos do trabalho, políticas de emprego e de proteção social. Na afirmação da COMISSÃO ECONÔMICA PARA A AMÉRICA LATINA E CARIBE; PROGRAMA DAS NAÇÕES UNIDAS PARA O DESENVOLVIMENTO; ORGANIZAÇÃO INTERNACIONAL DO TRABALHO (Cepal/PNUD/OIT), para que o trabalho seja considerado decente seria necessário avançar em quatro pontos-chaves: a geração de mais e melhores empregos, a extensão da proteção social, o respeito aos direitos trabalhistas e a existência de espaços e mecanismos de diálogo social envolvendo governos, trabalhadores e empregadores.

Em 2008, a Organização das Nações Unidas anunciou uma nova meta do Milênio, no caso "atingir o pleno emprego produtivo e o trabalho decente para todos, em particular para as mulheres 
e os jovens" (COMISSÃO ECONÔMICA PARA A AMÉRICA LATINA E CARIBE, 2008a, p. 113), como parte do primeiro Objetivo de Desenvolvimento do Milênio de erradicar a pobreza extrema e a fome. A própria Cepal reconhece que, mesmo se tratando de um objetivo quantitativo com uma série de indicadores e metas que devem ser alcançados em um determinado tempo, se evidenciou que a necessidade de "melhorar" o mercado de trabalho é uma constante preocupação para todos os países da região.

A promoção de políticas para o emprego decente pressupõe, segundo a Cepal/Pnud/OIT, a junção de cinco eixos fundamentais: 1) assegurar o crescimento econômico sustentado; 2) respeitar os direitos fundamentais do trabalho; 3) ampliar a proteção social; 4) promover a igualdade e combater a discriminação e 5) fortalecer o diálogo social. O problema parece situar-se justamente nestes eixos. O crescimento econômico é historicamente o responsável pela precarização do trabalho e tem se demonstrado sustentável para os grupos de poder político-econômico e para o processo de desenvolvimento do capital.

De outra parte, o respeito aos direitos fundamentais do trabalho, assim como o direito à proteção social, deteriorou-se rapidamente no processo de reestruturação produtiva, sendo que o papel do Estado tem sido o de terceirizar de forma mediada tanto os direitos do trabalho - estimulando não só a precarização do trabalho através da informalidade - como também a abertura de postos de trabalho por essa via; e, como se não bastasse, criam-se políticas que sustentam esse viés, como por exemplo, o incentivo à privatização de vários serviços de proteção social, como a saúde e a previdência. Tomemos por caso extremo o exemplo argentino, em que a previdência se encontra praticamente em mãos da iniciativa privada.

Para os trabalhadores que conseguem permanecer empregados, a situação também se dificultou. O crescimento significativo 
da produção e um ritmo muito acelerado da mão-de-obra excedente atuou como elemento de rebaixamento dos salários, da crescente perda dos direitos tradicionalmente adquiridos (sindicais, legislação trabalhista, etc), levando a um processo de precarização das relações de trabalho, através do qual se pretende reduzir ao mínimo possível os direitos e garantias que o trabalho havia conquistado historicamente.

Cepal/PNUD/OIT reconhecem que o crescimento econômico não garante, por si só, a promoção do trabalho decente e do desenvolvimento humano, "o incremento intenso e sustentado da produção estimula a demanda por mão-de-obra e amplia as possibilidades de formalização. Por isso, torna-se um pré-requisito para a geração de mais e melhores empregos" (COMISSÃO ECONÔMICA PARA A AMÉRICA LATINA E CARIBE; PROGRAMA DAS NAÇÕES UNIDAS PARA O DESENVOLVIMENTO; ORGANIZAÇÃO INTERNACIONAL DO TRABALHO, 2008, p. 107).

Para acelerar o crescimento com empregos de qualidade, é preciso um aumento sustentado do investimento público e privado, a dinamização do mercado interno e uma inserção adequada na economia internacional. Esses desafios precisam ser pensados no contexto de uma economia globalizada, com uma estrutura produtiva diversificada e competitiva (COMISSÃO ECONÔMICA PARA A AMÉRICA LATINA E CARIBE; PROGRAMA DAS NAÇÕES UNIDAS PARA O DESENVOLVIMENTO; ORGANIZAÇÃO INTERNACIONAL DO TRABALHO, 2008, p. 108).

Mais uma vez as fórmulas cepalinas tentam convencernos que o hiato do problema se encontra no desenvolvimento econômico. Afinal, qual desenvolvimento econômico a Cepal se refere? Conforme apontado pela Cepal, se o desenvolvimento econômico se dá através da criação de novos postos de trabalho, necessariamente isto implicaria numa ocupação pela via do trabalho decente? E, ainda, a criação desses postos de trabalho implicaria 
na redução dos índices de pobreza e indigência? Realizaremos, na continuidade, algumas reflexões sobre a base de sustentação da concepção cepalina e, particularmente, sobre a construção de indicadores sociais por ela abordados.

Aferir indicadores complexos como os do emprego produtivo e do trabalho decente que fazem parte da nova meta do Milênio é um desafio que ainda está por realizar-se. Os indicadores oficiais propostos pela Organização Internacional do Trabalho e o grupo de especialistas das Nações Unidas apontam para quatro elementos essenciais para acompanhar a meta do emprego decente: a) taxa de crescimento do PIB por pessoa empregada; b) relação emprego - ocupação (taxa de ocupação); c) percentual da população ocupada com renda inferior a 1 (um) dólar por dia e d) percentual da população que trabalha por conta própria ou em empresa familiar.

A partir dos pressupostos da ONU, a Cepal afirmou que na América Latina desde 1990, e, em particular, com maior ênfase depois de 2003, três indicadores identificados como básicos para avaliar as metas de Desenvolvimento do Milênio têm demonstrado índices favoráveis: o aumento da produtividade do trabalho, o aumento das taxas de ocupação e a diminuição da pobreza entre os ocupados (COMISSÃO ECONÔMICA PARA A AMÉRICA LATINA E CARIBE, 2008a, p. 113). Toda a argumentação cepalina sobre a melhoria do acesso ao trabalho se sustenta sobre estes três indicadores. Vejamos, então, como se produziu essa análise.

\section{A produtividade do trabalho}

O indicador considerado pela OIT como o primeiro para avaliar e acompanhar o crescimento do trabalho produtivo e o trabalho decente é a taxa de crescimento do PIB por ocupado, indicador este que pode ser utilizado para avaliar se 
as condições econômicas de um país permitem gerar e manter oportunidade de emprego com remuneração justa. A melhoria desse indicador reduziria as taxas de pobreza (ORGANIZAÇÃO INTERNACIONAL DO TRABALHO, 2008, p. 17). Mesmo assim, na América Latina o baixo crescimento da produtividade do trabalho desde o início da década de 1990 não conseguiu reduzir as taxas de extrema pobreza. Entre 1992 e 2006, o valor agregado por posto de trabalho demonstrou uma média de crescimento anual de 0,6\% para o conjunto de 18 países latino-americanos. (Ver Tabela 2).

\section{Tabela 2. América Latina (18) países. Taxa Anual Média do Crescimento do PIB por Ocupado - Percentuais.}

\begin{tabular}{|l|r|r|r|}
\hline \multicolumn{1}{|c|}{ País } & $\mathbf{1 9 9 2} \mathbf{- 2 0 0 2}$ & $\mathbf{2 0 0 3} \mathbf{2 0 0 6}$ & $\mathbf{1 9 9 2} \mathbf{2 0 0 6}$ \\
\hline Argentina & 0,1 & 4,6 & 1,3 \\
\hline Bolívia & $-0,3$ & 1,0 & 0,0 \\
\hline Brasil & 0,2 & 2,0 & 0,7 \\
\hline Chile & 3,8 & 4,9 & 4,1 \\
\hline Colômbia & $-0,8$ & 1,3 & $-0,3$ \\
\hline Costa Rica & 1,4 & 2,1 & 1,5 \\
\hline Equador & $-1,6$ & 0,9 & $-1,0$ \\
El Salvador & 1,5 & 0,9 & 1,4 \\
\hline Guatemala & 1,6 & 0,6 & 1,3 \\
\hline Honduras & $-1,2$ & $-2,5$ & $-1,6$ \\
\hline México & 0,1 & 1,9 & 0,6 \\
\hline Nicarágua & $-1,4$ & $-0,1$ & $-1,1$ \\
\hline Panamá & 0,2 & 3,8 & 1,1 \\
\hline Paraguay & $-2,2$ & $-1,0$ & $-1,9$ \\
\hline Peru & 0,3 & 3,8 & 1,2 \\
\hline Rep. Dominicana & 3,3 & 1,9 & 3,0 \\
\hline Uruguay & $-0,4$ & 5,4 & 1,1 \\
Venezuela & $-2,2$ & 2,8 & $-0,9$ \\
\hline
\end{tabular}

Fonte: CEPAL. Panorama Social de América Latina 2008. p. 117. 
Como mostra a Tabela 2, estes dados ocultam realidades bem diferentes, desde o caso do Chile, com um crescimento de 4,1\% anual, até o caso do Paraguai onde a produtividade baixou para uma média de 1,9\% anual. Para a Cepal, a média da produtividade não cresceu até 2002; no período de 2003 a 2006 esta se desenvolveu em uma média anual de 1,9\%. Assim, deve-se considerar que, desde o início da década de 1990 e repetindo-se nos anos de 2003 a 2006, o aumento da taxa de ocupação na América Latina ocorreu no setor de comércio e serviços, sendo esta a que representa a maior parte dos novos postos de trabalho, geralmente de má qualidade, com alta informalidade e com um grande percentual de trabalho por conta própria.

A Cepal apresentou variadas análises no decorrer do período que vai de 1999 até 2002 sobre a produtividade do trabalho. No final da década de 1990, a queda da produtividade do trabalho devia-se ao aumento do emprego informal. "Em 1999 o emprego por conta própria aumentou 2,6\% e o emprego doméstico 7,1\%" (COMISSÃO ECONÔMICA PARA A AMÉRICA LATINA E CARIBE, 2000, p. 90). O enfraquecimento da oferta de trabalho expressou-se em uma baixa geração de emprego assalariado, coincidindo com uma elevada taxa de auto-geração de emprego por conta própria.

Destacou-se que a baixa qualidade do emprego em 1999 ocorreu como um problema derivado da diminuição da demanda de emprego, afetando principalmente o Chile, Colômbia, Honduras, Peru e Uruguai. Assim, o aumento do emprego no comércio, que significou $27 \%$ do total gerado em 1999, deveu-se à expansão das atividades informais (COMISSÃO ECONÔMICA PARA A AMÉRICA LATINA E CARIBE, 2000, p. 93). No ano de 2000, a Cepal atribuía a baixa produtividade do trabalho ao aumento da informalidade, à queda da oferta de emprego assalariado formal e à precarização do salário e dos novos postos de trabalho criados. 
Em 2003, a Cepal atribuía a responsabilidade pela baixa produtividade do trabalho à queda da taxa de ocupação, à pouca oferta de emprego formal, sendo que os novos postos de trabalho corresponderiam ao trabalho informal. O desemprego urbano aumentou aproximadamente em um milhão de pessoas e a taxa de desemprego atingiu um máximo histórico de 8,9\% da força de trabalho (COMISSÃO ECONÔMICA PARA A AMÉRICA LATINA E CARIBE, 2003, p. 31). Estes últimos quatro elementos seriam os responsáveis pela baixa produtividade que, segundo a Cepal, não se agravou porque o controle da inflação foi adequado.

A Cepal avaliava, em 2005, a produtividade do trabalho a partir da diminuição da taxa de desemprego de 2004 , de 10,7\% para $10,0 \%$. Isto incidiu em quase todos os países latino-americanos na sua taxa de ocupação, que avançou de $52,2 \%$ para $52,8 \%$ do total da população em idade de trabalhar. "Como reflexo da reativação do aparelho produtivo, a maioria dos novos postos de trabalho corresponderam ao emprego assalariado e em muitos países se expandiu o emprego formal" (COMISSÃO ECONÔMICA PARA A AMÉRICA LATINA E CARIBE, 2005, p. 110). Assim, o novo milagre do mercado de trabalho iniciava uma nova fase extremamente promissora. Neste momento foi que os técnicos das Nações Unidas começaram a insistir no que seria posteriormente um dos novos Objetivos do Milênio: atingir o pleno emprego e o emprego decente.

Em 2007, as análises sobre a produtividade no trabalho passaram para um segundo plano, visto que o tema da hora era exaltar a recuperação econômica e do mercado de trabalho:

A expansão econômica deu lugar a um aumento da demanda de trabalho, o que se refletiu em um significativo aumento do emprego formal. Graças a isso, continuou o aumento da taxa de ocupação iniciada em 2003, que acumulou um incremento de dois pontos percentuais, em um processo liderado pela geração 
de emprego assalariado, que vem crescendo em média 3,7\% ao ano (COMISSÃO ECONÔMICA PARA A AMÉRICA LATINA E CARIBE, 2007, p. 21).

O que os dados da Cepal omitem são as "características" dos novos postos de trabalho do período, criados pela via da precarização, ou seja, da informalidade, que mal aparecem em suas análises. O destaque foi para a diminuição do desemprego e para o aumento das taxas de ocupação vinculadas ao emprego formal. A produtividade do trabalho identificou-se com diversos fatores relacionados ao mercado de trabalho e ao crescimento econômico e não ao tipo de emprego gerado, ou seja, desvinculando o conceito de produtividade do trabalho do aspecto formal e informal dos novos postos de trabalho gerados. Quando se analisam indicadores relacionados com a produtividade se faz necessário observar o restante dos indicadores formais - taxas de ocupação e tipos de trabalho gerados - porque a tendência - em particular da Cepal e de outras organizações congêneres - é de ofuscar as informações em beneficio das tabelas estatísticas, o que resulta em análises no mínimo simplistas.

\section{O aumento das taxas de ocupação}

A taxa de ocupação - ou relação ocupação-população é definida com base no percentual da população em idade de trabalhar que está ocupada. Esta seria uma medida que concentraria tanto a participação da população no mercado de trabalho como a capacidade de uma economia de absorver a força de trabalho. A própria Cepal reconhece que, nos países com elevadas taxas de desemprego, geralmente as taxas de ocupação são altas, isto se deve ao fato de que os novos empregos gerados possuem baixa qualidade, estando na sua maioria na informalidade, o que é comum nos países mais pobres (COMISSÃO ECONÔMICA PARA A AMÉRICA LATINA E CARIBE, 2008a, p. 119). 
De forma conjunta, as novas tecnologias e as novas formas de organização do trabalho vão permitindo o aumento substancial da produtividade, que, como resultado imediato, incrementou a elevação da crescente dispensa de mão-de-obra. Assim, o aumento da produtividade não tem levado a um crescimento do emprego capaz de absorver uma boa parte da mão-de-obra excluída do sistema produtivo. Desta maneira, o sistema criou mecanismos de exclusão social, que se tornaram exclusão estrutural. Os indicadores de desemprego - que se apresentam em fase de notória diminuição - mascaram o cenário real: mais empregos foram criados no período 2003 - 2006, só que de baixíssima qualidade.

Observe-se na Tabela 3 os percentuais nacionais de ocupação na América Latina apresentados pela Cepal. Note-se que as taxas aumentaram na grande maioria dos 18 países participantes da pesquisa. Se a taxa de ocupação aumentou, como se explica que os indicadores de pobreza e desemprego não acompanharam esta "evolução"? Segundo a Cepal, o aumento da taxa de ocupação entre 2002 e 2006 se relaciona com uma maior participação das mulheres no mercado de trabalho em detrimento dos homens, o que não necessariamente implica em diminuição da pobreza, pois os contingentes femininos passam a ser incorporados nos setores de prestação de serviços, caracterizados pela informalidade e precarização, o que beneficia a tendência de desregulamentação do trabalho. Além disso, à medida que as mulheres foram percentualmente mais ocupadas no período, os indicadores também mostram que os homens passaram a engrossar as filas dos desempregados em igual proporção. 
Tabela 3. América Latina (18) países. Taxa de Ocupação Totais Nacionais - Percentuais.

\begin{tabular}{|l|r|r|r|}
\hline \multicolumn{1}{|c|}{ País } & $\mathbf{1 9 9 0}$ & $\mathbf{2 0 0 2}$ & \multicolumn{1}{|c|}{$\mathbf{2 0 0 6}$} \\
\hline Argentina & 52,5 & 49,0 & 57,0 \\
\hline Bolívia & 53,5 & 61,5 & 63,4 \\
\hline Brasil & 61,1 & 60,8 & 63,2 \\
\hline Chile & 47,7 & 50,1 & 53,1 \\
\hline Colômbia & 58,6 & 56,2 & 57,5 \\
\hline Costa Rica & 54,7 & 55,9 & 57,1 \\
\hline Equador & 57,1 & 60,6 & 62,7 \\
\hline El Salvador & 55,8 & 56,1 & 55,5 \\
\hline Guatemala & 56,5 & 66,5 & 61,2 \\
\hline Honduras & 56,1 & 57,8 & 58,1 \\
\hline México & 52,1 & 59,2 & 62,2 \\
\hline Nicarágua & 49,6 & 58,3 & 60,4 \\
\hline Panamá & 48,1 & 54,1 & 58,8 \\
\hline Paraguay & 61,4 & 59,9 & 64,3 \\
\hline Peru & 67,9 & 64,5 & 66,2 \\
\hline Rep. Dominicana & 52,9 & 53,3 & 54,1 \\
\hline Uruguay & 52,6 & 50,2 & 52,4 \\
\hline Venezuela & 51,6 & 58,0 & 59,5 \\
\hline
\end{tabular}

Fonte: Elaborada a partir de dados da CEPAL. Panorama Social de América Latina 2008. p. 119.

Deve-se considerar como elemento relevante que o aumento das taxas de ocupação se relaciona também com o aumento do trabalho vulnerável. Na América Latina, o percentual de trabalhadores "ocupados" vulneráveis aumentou de 33,0\% em 1990 para 33,7\% em 2006. Na maioria dos países do continente, o percentual de trabalhadores por conta própria e do trabalho familiar não remunerado aumentou consideravelmente e isto certamente influiu sobre o aumento da taxa de ocupação. $\mathrm{O}$ problema não está em debater dados estatísticos e, sim, em evidenciar a vulnerabilidade desde tipo de ocupação. Ou seja, de que tipos de trabalho estão falando? 
A Cepal afirmou em 2007 que, independentemente dos métodos utilizados para medir o coeficiente de emprego formal e informal, "[...] todas as medições indicam que a reativação econômica dos últimos anos se traduziu em um aumento absoluto e relativo do emprego formal" (COMISSÃO ECONÔMICA PARA A AMÉRICA LATINA E CARIBE, 2007, p. 24). Isto implicou que as taxas de ocupação aumentaram e com elas segundo a Cepal - a qualidade do emprego, visto que grande parte desses empregos gerados era assalariado, formal e com contratos de trabalho que garantiam a proteção social. O que se omitiu foi que justamente neste período se estimulou massivamente no âmbito da América Latina o emprego por conta própria, o que obviamente não se menciona nos relatórios da Cepal.

Em pesquisa realizada com cinco países do continente (Colômbia, Equador, México, Panamá e Peru) pela Organização Internacional do Trabalho em 2009 - fonte esta que fornece informações para a Cepal -, estimou-se que, no ano de 2007, o emprego informal na área urbana destes países foi de 58,5\% (média simples). O que o estudo evidenciou foi a diferença significativa entre os países: no caso de Colômbia e Peru o emprego informal esteve composto por trabalhadores por conta própria, 53,6\% no primeiro caso e 45,3\% no segundo. Já no Equador e México, representou 53,3\% para o primeiro e $62,7 \%$ para o segundo. No Panamá, a incidência do emprego informal foi de 44,8\% (ORGANIZAÇÃO INTERNACIONAL DO TRABALHO, 2009, p. 19).

Os dados da Cepal apontam um aumento das taxas de ocupação em relação ao trabalho vulnerável, ressaltando que nas áreas rurais dos países latino-americanos se registra o maior percentual de trabalhadores familiares não remunerados, passando de 50\% do total de ocupados e, nas áreas urbanas, estes representam em média 30\% dos trabalhadores ocupados. Isto pode explicar com mais consistência o aumento das taxas de 
ocupação: a precarização do trabalho também contribui para o aumento da ocupação e para o aumento e manutenção da pobreza e da indigência.

\section{A diminuição da pobreza entre os ocupados}

A OIT afirmou em 2007 que, se os trabalhadores não conseguem gerar uma renda suficiente para poder sair da extrema pobreza junto com suas famílias, dificilmente seus empregos podem ser definidos como "decentes" (ORGANIZAÇÃO INTERNACIONAL DO TRABALHO, 2008, p. 38). No entender do Banco Interamericano de Desenvolvimento (2007), ser um trabalhador pobre ou indigente não significa necessariamente obter baixa renda, visto que um trabalhador com boa renda pode situar-se abaixo da linha de pobreza se no seu lar existe um número elevado de dependentes (BANCO INTERAMERICANO DE DESENVOLVIMENTO, 2008, p. 37).

O indicador utilizado para o acompanhamento da meta de emprego no âmbito mundial é calculado pela OIT como a média ponderada de: 1) o produto da incidência da extrema pobreza medida pelo Banco Mundial segundo a base de um dólar diário de renda - e a população maior de 15 anos de idade e 2) o produto entre a incidência da extrema pobreza e a força de trabalho maior de 15 anos $^{4}$. Na América Latina e no Caribe o percentual de trabalhadores que vivem com menos de um dólar por dia, calculado com esta metodologia, diminuiu mais de três pontos percentuais, passando de 11,6\% em 1997 para 8,0\% em 2007 (COMISSÃO ECONÔMICA PARA A AMÉRICA LATINA E CARIBE, 2008c, p. 11-23).

\footnotetext{
${ }_{4}$ Este método de cálculo representa uma aproximação, que resulta de mediar a estimativa 1) em limite superior e 2) em um limite inferior do verdadeiro percentual de ocupados extremamente pobres. A estimativa do limite inferior tem como base o pressuposto de que todos os pobres maiores de 15 anos são parte da população economicamente ativa ocupada. Nações Unidas. Indicadores de los Objetivos del Mileño. In: CEPAL. Panorama Social de América Latina 2008, p. 119-123.
} 
Segundo o método da Cepal em Panorama Social de América Latina, para medir a indigência e a pobreza - não utilizando a linha de um dólar por dia -, constroem-se categorias para cada país em particular. A diferença da metodologia utilizada pela OIT para o cálculo do indicador oficial, neste caso a indigência e a pobreza entre os ocupados, é retirada diretamente dos dados de entrevistas em lares, realizadas pelos respectivos institutos de estatística e censos de cada país.

A Cepal apresenta dados para América Latina (18 países) nos quais em 1990 se registrou um percentual de 39,7\% de trabalhadores ocupados em situação de pobreza ou indigência, passando para 35,6\% em 2002 e para 29,5\% em 2006 (COMISSÃO ECONÔMICA PARA A AMÉRICA LATINA E CARIBE, 2008 a, p. 120). Segundo estas informações, $7 \%$ dos trabalhadores ocupados no Chile vivem em condições de pobreza e em Honduras esta cifra representa $63 \%$. Ainda, dos trabalhadores ocupados, $1 \%$ no Chile e $40 \%$ em Honduras vivem em situação de indigência.

Argumenta-se que, segundo uma tendência regional (América Latina), entre 1990 e 2006 os índices de indigência de trabalhadores ocupados diminuíram de $17,5 \%$ para $11,4 \%$ respectivamente. Para o mesmo período, a Cepal afirma que a diminuição da pobreza entre os trabalhadores ocupados cedeu 18 pontos percentuais no Chile. Já no Brasil e no México a diminuição foi de 14 pontos percentuais. As exceções seriam os casos de Argentina e Uruguai, onde se registrou um "leve aumento" da pobreza entre os trabalhadores ocupados e, na Bolívia e no Paraguai, onde a pobreza entre os trabalhadores ocupados aumentou ao redor de quatro pontos percentuais.

Na análise da OIT (ORGANIZAÇÃO INTERNACIONAL DO TRABALHO, 2009), estimou-se que todos os países latino-americanos registrariam em 2009 uma redução das taxas de crescimento do PIB: Argentina lideraria o processo de 
desaceleração passando de 6,8\% em 2008 para 2,6\% em 2009, enquanto que o Brasil reduziria de 5,9\% de 2008 para 2,1\% em 2009. Uruguai, que liderou o crescimento regional em 2008 com $11,4 \%$, fecharia 2009 com uma expansão de 4,0\%. Peru, com um crescimento estimado em $5 \%$, seria o país latino-americano com maior crescimento estimado para 2009, seguido por Nicarágua com 4,5\%, República Dominicana com 4,0\%, Bolívia e Venezuela com $3 \%$ cada um. O restante dos países registraria crescimentos entre $2,6 \%$ e $1,0 \%$, salvo o México, que se estima que tenha o menor desempenho, com 0,5\% (ORGANIZAÇÃO INTERNACIONAL DO TRABALHO, 2009, 40).

\section{Considerações Finais}

As análises acerca do trabalho e emprego na América Latina, apresentadas a partir de indicadores sociais discutidos pela Cepal, constituem-se em uma referência para os governos latino-americanos pensarem o desenvolvimento econômico nos países do continente. Em virtude disso, o estudo focou essas análises com objetivo de compreender os conceitos e parâmetros acerca da categoria trabalho utilizados pela Cepal. Segundo dados oficiais apresentados pela Cepal, entre 2002 e 2007 registrou-se na América Latina uma diminuição do desemprego de 11\% para $8 \%$, o que leva a uma tendência de crescimento econômico com a criação de novos postos de trabalho e, conseqüentemente, uma diminuição nos índices de pobreza.

Porém, ao observarmos as informações trazidas pela Cepal verificamos que os indicadores de pobreza não diminuem na mesma proporção em que diminuem os índices de desemprego. Nessa perspectiva, procuramos decifrar os parâmetros utilizados pela Cepal ao afirmar a tendência de desenvolvimento econômico e geração de novos postos de trabalho na América Latina. As interpretações cepalinas acerca do trabalho precarizado 
apresentam uma velha polêmica: a da separação de uma categoria em duas, ou seja, de um lado estão os trabalhadores inseridos em trabalhos vulneráveis e, de outro, os trabalhadores em setores de baixa produtividade.

Os técnicos da Cepal, em suas análises, separam categorias que são essencialmente inseparáveis. Isto porque trabalhadores vinculados a setores de baixa produtividade também podem ser considerados trabalhadores vulneráveis, afinal, não há diferenças substanciais entre essas categorias. Os parâmetros construídos para apresentar os dados referentes à inserção de trabalhadores em postos de trabalho consistem em mostrar o trabalho informal desvinculado do trabalho precarizado e, conseqüentemente, do trabalho vulnerável e de baixa produtividade, o que, logicamente, faz diminuir os índices de desemprego.

O fenômeno do trabalho informal no contexto latinoamericano é explicado pelos técnicos da Cepal como produto dos altos custos do emprego estável, segurado e amparado pelas legislações trabalhistas e, conseqüentemente, a tendência da precarização do trabalho torna-se inevitável e legítima em seu discurso. As explicações produzidas pela Cepal acerca do trabalho informal alinham-se ideologicamente com a perspectiva neoliberal, que justifica a exploração do trabalho em prol da desoneração do Capital e do Estado diante dos custos do trabalho formal.

As análises cepalinas insistem em convencer-nos de que há uma produtividade do trabalho, o que de fato há, mas tal fato constitui-se em meias verdades, pois o aumento da produtividade do trabalho não leva necessariamente a uma remuneração justa e, conseqüentemente, à melhoria da qualidade de vida dos trabalhadores. Se a produtividade do trabalho se dá pelo viés da precarização, da informalidade e da vulnerabilidade, concretamente oposto ao trabalho decente, o que há de fato é um incremento de exploração da força de trabalho em prol de um desenvolvimento 
econômico desigual, que mantém e reproduz altos índices de pobreza e indigência entre os trabalhadores.

Submetido em 30 de outubro de 2009 e aceito para publicação em 30 de março de 2010

\section{Referências}

BANCO INTERAMERICANO DE DESENVOLVIMENTO. Progreso Económico y Social en América Latina. Informe 2008: Cambios en los Patrones de Exclusión en América Latina y el Caribe. Washington D.C., 2008.

COMISSÃO ECONÔMICA PARA A AMÉRICA LATINA E CARIBE. Panorama Social de América Latina 2008. Santiago de Chile, 2008.

COMISSÃO ECONÔMICA PARA A AMÉRICA LATINA E CARIBE. Anuário Estatístico de América Latina y del Caribe 2008. Santiago de Chile: Cepal, 2008.

COMISSÃO ECONÔMICA PARA A AMÉRICA LATINA E CARIBE. Objetivos de Desarrollo del Milenio. La Progresión hacia el Derecho a la Salud en América Latina y el Caribe. Santiago de Chile, 2008.

COMISSÃO ECONÔMICA PARA A AMÉRICA LATINA E CARIBE. Estudios Económicos de América Latina y el Caribe 1999-2000. Santiago de Chile, 2000.

COMISSÃO ECONÔMICA PARA A AMÉRICA LATINA E CARIBE. Estudios Económicos de América Latina y el Caribe 2002-2003. Santiago de Chile, 2003.

COMISSÃO ECONÔMICA PARA A AMÉRICA LATINA E CARIBE. Estudios Económicos de América Latina y el Caribe 2004-2005. Santiago de Chile, 2005.

COMISSÃO ECONÔMICA PARA A AMÉRICA LATINA E CARIBE. Estudios Económicos de América Latina y el Caribe 2006-2007. Santiago de Chile, 2007.

COMISSÃO ECONÔMICA PARA A AMÉRICA LATINA E CARIBE; PROGRAMA DAS NAÇÕES UNIDAS PARA O 
DESENVOLVIMENTO; ORGANIZAÇÃO INTERNACIONAL DO TRABALHO . Emprego, Desenvolvimento Humano e Trabalho Decente: a experiência brasileira recente. Santiago de Chile, 2008.

SADER, E. A Vingança da História. São Paulo: Boitempo, 2003.

ORGANIZAÇÃO INTERNACIONAL DO TRABALHO. Panorama Laboral 2007 de América Latina y el Caribe. Lima: Oficina Regional para América Latina y el Caribe, 2008.

ORGANIZAÇÃO INTERNACIONAL DO TRABALHO. Panorama Laboral 2008 de América Latina y el Caribe. Lima: Oficina Regional para América Latina y el Caribe, 2009. 